\title{
Terminology and Transliterations
}

Although Oriental was the common term used to describe East Asians in America (Chinese, Japanese, and Korean Americans) until recent times, I choose to use Asian American for political reasons and not to hyphenate Chinese American even when used as an adjective. During the late I960s, Chinese and Japanese American activists called attention to Oriental as a derogatory name that connotes exoticism and inferiority. The term Asian American became the preferred name in recognition of the group's common history of oppression, geographical origins, panethnic identity, and political destiny. The hyphen was eliminated because it inferred that Chinese Americans have split identities, that somehow they are not fully American like everyone else. For the same reasons and to be consistent, I do not use the hyphen when referring to any ethnic American group.

In regard to racial and ethnic terms, I use what is generally preferred by the groups themselves. Black and African American are used interchangeably; so are Native American and American Indian. Depending on the time period under discussion, I use either Latino, Hispanic, Mexican, or Chicano; minority women or women of color. In a racial context, I generally use white instead of European American. Otherwise, I try to be ethnic specific in identifying the group by using Italian American, German American, Jewish American, etc. I capitalize Black but not white in recognition of the distinctive history, cultural identity, and political legacy that the former but not the latter term encompasses. The 
term America should be understood as an abbreviated form of United States of America. To be Americanized is to become acculturated but not necessarily assimilated into American life. To avoid the trap of associating the dominant white group with everything that is American, Western is preferred over American when the reference is to cultural practices; thus, Western dress, not American dress.

I call the first generation those who were foreign-born and came to the United States as immigrants, and their children who were born in the United States second generation or American-born Chinese. When referring to both groups, I use either Chinese in America or Chinese Americans, especially when I need to differentiate them from the Chinese in China. For example, when comparing women in China and Chinese women in America, I use Chinese women for the former group and Chinese American women for the latter. Overseas Chinese is used instead of Chinese Americans when the reference point is in China.

Following standard practice, I use the pinyin romanization system for Chinese proper nouns, except in cases where the names have been commonly spelled in a different romanization system, such as Sun Yat-sen and Macao. For common words and phrases in the Cantonese dialect or direct quotes from Cantonese-speaking persons, I use the Cantonese spelling according to Sidney Lau's A Practical Cantonese-English Dictionary (Hong Kong: The Government Printer, 1977). Place-names in Cantonese are followed by the pinyin spelling whenever deemed helpful; for example, Chungshan (Zhongshan) District. All Chinese proper nouns and terms mentioned in this book are recorded in the Glossary in the appendix, together with their Chinese characters. In addition, Chinese terms are generally defined at their first appearance in the text.

When using a person's Chinese name, I follow Chinese practice by giving the surname (family name) first, followed by the given name (usually two characters), without an intervening comma. For example, in the name Tom Yip Jing, Tom is the surname and Yip Jing, the given name. Exceptions occur when a particular individual (e.g., Joe Shoong) chooses to reverse the order to conform with Western usage. Without meaning to be disrespectful, I generally use the person's given name instead of his or her last name whenever I refer to him or her more than once in the text. Since many Chinese Americans share the same surname, I adopted this practice to avoid confusion. The appearance of Shee in a woman's name indicates that she is married. For example, a woman with the maiden name of Law who married into the Low family would thenceforth be known as Law Shee Low. 
Chinese dates prior to the adoption of the Western calendar in 1949 are rendered according to the Chinese lunar calendar, followed by the corresponding Western date in parentheses. Before the establishment of the Chinese Republic in I9I 2, Chinese dates were reckoned by the emperor's reign; for example, K.S. 33/IO-I 3 meant in the $33 \mathrm{~d}$ year of Emperor Kuang Su's reign, Ioth month, 13 th day (November 18 , 1907). Beginning in 1912 , Chinese dates went by the name of the new republic; for example, CR 26-I-20 meant in the 26th year of the Chinese Republic, Ist month, 2oth day (March 2, I937). In converting Chinese dates into Western dates I followed Liang Qi and Hua Chao, eds., Zhongxi duizhao yinyang bebi wannianli (Ten-thousand-year calendar: a comparison of Chinese and Western dates) (Hong Kong: Shanghai Book Store, 1984).

Finally, although it is standard practice to indicate spelling and grammatical errors in quoted passages by the use of "[sic]," I chose to forgo doing so in many instances in order to remain faithful to the exact wording and style of speech, and to avoid interrupting the flow of the conversation. 
